\title{
Managing criminal acts on the psychiatric ward: understanding the police view
}

\author{
Richard Bayney \& George Ikkos
}

Abstract Success in preventing and responding to criminal behaviours on psychiatric wards may sometimes require cooperation between mental health services and local police services. This is especially so when seeking legal remedies through the criminal justice system. This article describes police perceptions of psychiatric services and psychiatric patients. It also reviews police procedures and factors that influence their response when the police are requested to intervene following an alleged criminal act by an in-patient. A case vignette is used to highlight the causes of tensions and guide the reader through the steps that might be considered when the issue of prosecution arises.

There appears to be increasing criminal activity within mental health settings. For example, there are reports of rising substance misuse and drug dealing. Violence on psychiatric wards is more common and accounts for the majority of the 60000 reported assaults against National Health Service (NHS) staff per year (UK Central Council for Nursing, Midwifery and Health Visiting, 2002).

Prevention of criminal behaviour should be pursued through a well-managed environment, workable treatment plans and local implementation of the Department of Health Zero Tolerance policy (Department of Health, 2000). Responses to criminal behaviours, once they have occurred, are influenced by a wide variety of factors, including the age, diagnosis, severity of illness and past psychiatric and forensic history of the patient and the previous management of similar situations. The personality, training, expectations and clinical setting of professionals, whether nurses, doctors, occupational therapists or others, will also affect the management of challenging behaviour in patients.

Difficulties have previously been recorded in the collaboration between mental health staff and the police, resulting in failure to achieve specific objectives, including appropriate prosecution. This article provides an overview of the issues involved when an in-patient is alleged to have committed a crime. A case vignette is used to emphasise key problems and obstacles that the police face and to analyse some of the reasons why tensions may arise between the police and mental health staff. The vignette presented is fictional, but faithfully reflects clinical reality. Any resemblance to an actual case is purely coincidental.

\section{The case vignette}

As the consultant on an adult mental health unit, a senior nurse manager asks to see you. She relays the following events. Mr. B is a 33-year-old in-patient with a history of persistent drug use over the past 14 years and convictions for supplying amphetamines and cocaine. He has two previous psychiatric admissions following amphetamine use. Shortly before admission, he was taking substantial quantities of amphetamines. Mr. B developed auditory hallucinations with paranoid delusions and was detained under Section 3 of the Mental Health Act 1983. He was commenced on antipsychotic medication and his symptoms resolved quickly. $\mathrm{Mr} \mathrm{B}$. said he would never use or supply illicit drugs again because they are dangerous and can cause illness. In week 3, he was granted leave under Section 17 of the Mental Health Act. On return yesterday, he was noted to be intoxicated and found in possession of cannabis resin and amphetamines. He punched a nurse when this was pointed out to him. He then admitted that he had been supplying drugs to other patients on the ward. You are asked to consider involving the police, as neither the victim nor other staff have done so.

Richard Bayney is a consultant psychiatrist at the Forensic Directorate, West London Mental Health Care Trust (Uxbridge Road, Southall, Middlesex UB1 3EU, UK. E-mail: Richard.Bayney@wlmht.nhs.uk). His research interests include issues of criminal behaviour_and responsibility in psychiatry. George Ikkos is a consultant psychiatrist at Edgware Hospital, Middlesex, Associate Medical Director, Barnet Enfield and Haringey Mental Health NHS Trust, and Chairman of the London Division of the Royal College of Psychiatrists. His research interests include issues of responsibility for behaviour in psychiatry, in the context of psychodynamic theories of transference and countertransference in the doctor-patient relationship. The authors are grateful to Inspector Bruce Frenchum, of the Community Safety and Partnership Policy Unit of the Metropolitan Police, London, for his advice. The opinions expressed in this article are those of the authors and not those of the police. 


\section{Implications of legal intervention via the police}

Within psychiatric wards, the decision to involve the police is often perceived as a last resort despite any victim or witness being free to report the crime. Factors affecting the decision include the nature and severity of the offence, previous criminal convictions and the personality of the patient (Smith \& Donovan, 1990). Others include the local inter-agency relationship with the police and a prior knowledge of police guidance on when to charge offenders. Finally, the existence of a local protocol guiding management of such situations, jointly agreed between the police and the NHS trust, may play an appreciable role in the decision.

There appear to be several benefits associated with police involvement. Miller \& Maier (1987) suggest that the process of prosecution may have a positive effect on staff morale despite the effort involved. Eastman \& Mullins (1999) emphasise that prosecuting patients may help increase their capacity to accept responsibility for their crime and aid future clinical risk assessment. One also should not forget that mental health staff suffer the same reactions as other victims of violence, and that ignoring this may increase the psychological trauma they experience and have a considerable impact on their health and performance at work (Engel \& Marsh, 1986). The decision to refer to the police, however, should not be undertaken lightly as there are disadvantages associated with this option. There are further disadvantages should the police be called out but decide not to take further action (Box 1).

\section{Provision of evidence}

A prerequisite of successful prosecution is evidence. Ward staff should have a basic awareness of methods of preserving and documenting evidence (Wick, 2000), perhaps in the form of local guidelines. On an in-patient unit, the key form of evidence tends to be the witness or the victim. Finding individuals, including patients, that are willing to give evidence about a crime and willing to go to court is often harder than it seems. Staff may be unprepared to make a statement or press charges (Hakeem \& Fitzgerald, 2002). Ryan \& Poster (1993) revealed that only $18 \%$ of nurses would take legal action if physically assaulted by a patient. When victims or witnesses

\section{Box 1 Disadvantages involved in legal action against psychiatric patients}

Disadvantages of seeking legal action

- If prosecution is pursued non-systematically, patients may believe that they are being victimised by staff

- There is no direct therapeutic value that can be ascribed to prosecution and punishment

- Patients may fail to understand why prosecution has occurred and feel that they are being punished unfairly

- The therapeutic alliance may be affected

- There is a possibility of imprisonment, which is likely to be anti-therapeutic

- In mental health units that function poorly there is a risk of scapegoating

- Prosecution may become a method of expelling unpopular patients

- Patients have the option of a countersuit

- There may be adverse publicity for the hospital

- Breaches of patient confidentiality occur

- Legal action can be relatively expensive for the public purse

- Opportunities to achieve positive effects from prosecution are limited

- The process can become time-consuming and impractical

Disadvantages when the police discontinue legal action after an initial investigation

- It excuses offending patients from accepting responsibility for their behaviour

- Patient offending that is neither confronted nor resolved may recur in the same or another facility

- There may be a decrease in staff morale and performance and possibly increased health problems

- Negative countertransference may be worsened

- There is no independent resolution of the facts, resulting in possibly biased clinical judgements about responsibility and guilt

- Victims cannot apply to the Criminal Injuries Compensation Board if there is no proof that the crime took place

- Relationships between the police and mental health services may deteriorate

- Further crimes may be likely to occur, leading to increased costs, particularly if staff are injured

- In the case of violence, the perception that being assaulted is part of the job may be reinforced 
are unwilling to proceed further, there is a significant reduction in the likelihood of prosecution.

\section{Provision of information}

Passing on confidential information about a patient to the police may bring allegations of a breach of Article 8 of the Human Rights Act 2000. In such circumstances, provision of information should be seen as a proportionate step in the interests of public safety, for the prevention of crime or disorder and for the protection of the rights and freedom of others. Similarly, sensitive data about a person's health can be provided to the police under the Data Protection Act 1998, if the processing is necessary for the administration of justice and is exercised in the public interest.

\section{Deciding to involve the police}

\section{The case vignette, continued}

You decide that it is necessary to involve the police, but are not sure how they will respond. On a previous occasion, the police officer did not have much experience of mentally ill patients and was not familiar with the notion of taking patients away from hospital. It also took some time for a response.

\section{Understanding influences \\ on the initial police response}

The responses to requests for police intervention depend on the interplay of several factors. A central issue underlying the initial response is that police officers may not be happy liaising with services about an incident that they do not perceive as a police problem (Dew \& Badger, 1999). When they attend, there are pressures on police officers not to be 'out of service' for extended periods while dealing with problems appearing to be mental health issues (Menzies, 1987). Other influences on the initial response include manner of communication, limitations of training and diversion of patients.

\section{Manner of communi cation}

The method of contact depends to some extent on the urgency of the situation. Discussions with local police will result in local protocols, detailing agreed methods of communication. Telephone referral to the police is more likely to be effective than written communication (Lund, 1999).

\section{Limitations of training}

Police officers come into contact with psychiatric patients on a regular and increasingly frequent basis
(Laberge \& Morin, 1995). They are trained in recognising and managing patients with mental disorders. When surveyed, however, few officers believed that they had sufficient training in mental illness (Carey, 2001). Many regard training as not particularly useful in practical situations and find that their education really occurs through experience (Dew \& Badger, 1999).

\section{Diversion of patients}

Current training of police officers focuses on an understanding of methods of diversion of patients with mental illnesses from the criminal justice system to the mental health system (Metropolitan Police Service, 1994). When there is a suggestion, therefore, that a particular offender may move in the opposite direction, i.e. from the mental health to the criminal justice system, uncertainty may result. Clarification that treatment on a psychiatric ward is not an impediment to prosecution, underpinned by the possibility of the patient's return to the psychiatric service should there be a need, might help resolve this uncertainty.

\section{The constable arrives}

\section{The case vignette, continued}

Constable A arrives to see Mr. B the following day. He is surprised that this referral has been made, as he believes that handling relatively low levels of violence is part of the ethos of mental health nursing. He regards the patient as having limited responsibility because of the associated mental disorder, and does not think that the Crown Prosection Service (CPS) will welcome legal action against $\mathrm{Mr}$. $\mathrm{B}$. He is unsure what he can do to help.

\section{Police perceptions of psychiatric services and psychiatric patients}

It is likely that police officers bring pre-existing assumptions when summoned to a psychiatric ward, and these may contribute to tension between the officers involved and mental health staff (Meadows et al, 1994). For instance, the police may believe that there will be inadequate support from mental health staff in the investigation and final handling of the case (Dunn \& Fahy, 1987). There are other issues that may influence police perceptions, and we outline two of these below with the intention of alerting mental health staff to pitfalls, explaining misunderstandings and defusing incipient tension.

\section{Responsibility of the patient}

Police officers might not realise that in some instances, mentally disordered offenders do have 
Box 2 Details required about the alleged offender and offence

Ward/Hospital

Patient's name

Patient's date of birth

Patient's hospital no.

Patient's legal status

Responsible medical officer (RMO)

Time and date of alleged offence

Description of events

Evidence in support of allegations

Witnesses to the offence

Willingness of victim/organisation to support prosecution

Relevant clinical issues, including diagnosis

Mental capacity of patient in relation to alleged offence

Has authority been given for patient to be taken from hospital if necessary?

Arrangements for rehospitalisation, if needed, if patient is transferred to the police station

Signature of RMO

Contact number of RMO

responsibility for their criminal behaviour, i.e. they understand the difference between right and wrong, have an awareness of what they are doing and exercise choice in their actions. Officers might implicitly associate deviant behaviour with mental disorder and conclude that some patients are immune from legal action because they have little or no responsibility for their actions. In these circumstances, guiding officers to a more sophisticated understanding of responsibility is required.

A report, best prepared by the responsible medical officer (RMO), may be the most appropriate solution in this situation (Box 2). It should elucidate the nature and degree of the mental disorder exhibited and the degree to which it has affected the judgement and capacity of the patient to exercise responsible behaviour. Another advantage of providing a report is that the police officer can forward it to the custody officer, the forensic medical examiner or the Crown Prosecution Service, should the patient be subject to subsequent proceedings.

\section{Ethics of prosecuting people with mental disorders}

Even though mental health staff have requested police intervention in an incident of unlawful activity, the police officer might (rightly or wrongly) believe that staff view arrest or prosecution of a patient as unethical. This notion is distilled through the perception of lack of responsibility mentioned above and the fact that within police guidance for prosecution, mental disorder is a factor weighted against prosecution. Other contributory beliefs are that the psychiatric hospital is responsible for controlling criminal behaviour exhibited by patients (Norko et al, 1991) and that being assaulted is an acceptable part of the mental health profession (Lanza, 1983). The onus is on staff to stress that they consider prosecution ethically acceptable when this is the case. It would also help if investigating officers were given copies of agreed local protocols.

\section{The role and powers of the police}

\section{The case vignette, continued}

It is not clear to staff why Constable A does not simply arrest the patient and investigate further at the police station. You are asked to see the officer to resolve the impasse and you convince him that a serious crime has been committed and that there is merit in further investigation. He asks for more information about the patient, but becomes apprehensive on learning that Mr. B is detained under the Mental Health Act 1983 , as he believes this limits his police power. It also turns out that Constable A has other concerns about safety in relation to removing the patient from hospital.

\section{Proportionality, safety and policing}

Successful dovetailing with the police requires a precise understanding of their role. A common misunderstanding is that the main or only role of the police is to enforce the law. In fact, the core role of the police officer is better viewed as maintaining order (Reiner, 1992), with the law being one tool for achieving this. Police officers have a significant margin of discretion. Arrest and prosecution are not automatic responses to offending behaviour. With regard to an in-patient with possible mental disorder, guidelines (e.g. Box 3 ) insist that it should be considered whether enforcement of the law is proportionate to the situation. Police officers also have enhanced concerns and preoccupations about safety.

\section{Place of safety}

Although place of safety is not technically at issue, the underlying principle remains an important concern. Police officers recognise a psychiatric in-patient ward as a place of safety, as defined in Section 135 (6) of the Mental Health Act 1983. They may be less likely, therefore, to move a patient who they believe has an illness and is being treated in the most appropriate place. In some cases, such as homicide, removal from the ward occurs readily, but in most situations the police officer will have to justify why he has taken the patient from a seemingly safer place. 


\section{Accountability of the police officer}

Should something untoward happen to the patient, or if the patient complains about removal from the ward, an automatic complaints investigation is initiated and the police officer has to formally account for the decision to transfer. Unease over disciplinary complaints and the accompanying investigations are further factors affecting the decision to convey a patient to the police station.

\section{Rehospitalisation following removal or arrest}

It is a common experience among police officers that, once they have removed a patient to a police station, hospital staff will prohibit the return of the patient to the ward following conclusion of police business. This is the case irrespective of whether the patient has been charged or not (Dew \& Badger, 1999). Tensions can then arise because the police regard the hospital as retaining an obligation to receive the patient or to arrange alternative accommodation, whereas hospital staff may desire cessation of treatment. One strategy that may be particularly helpful in assuaging police anxiety in relation to this is to confirm in advance that the patient is to be accepted back, where appropriate, to the same ward, a different ward or a more secure ward.

An important consideration is that removal from hospital is not always necessary or desirable. Under these circumstances, the police officer may proceed by way of summons, obliging the patient to appear in court at a specified time. A disadvantage of this approach is that if the patient is not taken to the police station promptly, there is less chance of eliciting the evidence. Another disadvantage is that the patient will not be subject to the jurisdiction of a custody officer, who normally gives high priority to

\section{Box 3 London Metropolitan Police guidelines on appropriate action}

The Metropolitan Police use five guidelines when dealing with a criminal act, based on the circumstances of the crime, but having regard for the safety and human rights of the individuals concerned. They are known as PLAN B:

Proportionate: is the action taken by the police officer proportionate to the seriousness of the crime?

Legal: is the action taken legal?

Accountable: can the police officer reasonably account for the action taken?

Necessary: is the action taken necessary to remedy the situation?

Based on best information: is the action based on the best information available?

\section{Box 4 Definition of breach of the peace}

A breach of the peace occurs when an act:

- is carried out that harms a person or his/her property; or

- is carried out that is likely to cause such harm; or

- is carried out that puts someone in fear of such harm; or

- is threatened to be carried out in a person's presence

ensuring that all rights are maintained under the Police and Criminal Evidence Act 1984 ( PACE). The alleged offender may also have the opportunity to influence witnesses.

\section{Powers available to the police officer}

Police officers can employ widespread powers in pursuit of their duty. The extent of police powers on psychiatric wards may not always be obvious to the police or to mental health staff. A common misunderstanding concerns the implications of detention of patients under the Mental Health Act. Police officers may be unsure whether such patients are exempt from arrest (Hakeem \& Fitzgerald, 2002). The reality is that if there is enough evidence, the officer can proceed with arrest, whether or not the patient is detained under another statute.

Besides the power of arrest, there is also a power to convey the patient from one location to another. In conducting an investigation into allegations of any criminal offence, police officers are subject to the Police and Criminal Evidence Act 1984 and its codes of practice. The Act states that if an officer has evidence to suspect a person of committing an offence, he or she must caution that person and inform him (her) of the right to a solicitor. On arrest, the person must be taken to a police station. If not arrested, the individual must be told that he (she) is free to leave at any time.

Restraining an agitated patient to contain further breaches of the peace (Box 4) is a power potentially open to the police officer. Conversely, assisting nurses in restraining a patient to allow administration of medication remains controversial and possibly illegal. Staff should not bear umbrage when officers decline to be involved under such circumstances.

\section{Removal to the police station}

\section{The case vignette, continued}

Constable A concludes his inquiries and is still not sure whether and how to proceed further. You ask him to contact his sergeant. You spend some time 
discussing the case with the sergeant, who is familiar with the locally agreed protocol and the patient is arrested and taken to the police station.

\section{Procedures at the police station}

Removal of a patient to a police station has a number of implications for police officers. One is that they may be apprehensive about the journey and may request that a nurse to accompany them. Although this is not always possible, the benefits include promoting better relations, improving collaboration and providing support and a reassuring base of knowledge. Other implications include the increase in the number of professionals, such as the custody officer, that the investigating officer will have to liaise with in the subsequent inquiries and the length of time such liaison may take.

\section{The custody officer}

On arrival at the station, the custody officer ensures that the patient's welfare is maintained. Custody officer training stresses that final decisions about an alleged offender should be informed by discussion with those most able to give advice. One measure facilitating this is to supply the contact numbers of the RMO or of the duty consultant outside of working hours. Referring mental health professionals should remain available to offer explanations and support, as liaison with the custody officer can be advantageous when attempting to secure an appropriate prosecution.

\section{The forensic medical examiner}

A mentally disordered offender taken under arrest to the police station must be examined by a forensic medical examiner to ascertain fitness to be detained and fitness to be interviewed (PACE, Section 66). It is good practice for the duty psychiatrist or the consultant psychiatrist to contact the examiner to explain the psychiatric history and why the patient has been taken from a psychiatric setting. Alternatively, and more practically, the contact numbers in the supplied report (Box 2) would allow the psychiatrist to be contacted by the examiner.

Fitness to be detained

The forensic medical examiner might conclude that further detention of the patient in the police station is likely to worsen his or her physical or mental condition. In this case, the examiner must give clear reasons for this and should suggest an alternative course of action. The final decision as to whether the patient faces further detention rests with the custody officer.

\section{Mental Health Act 1983 assessment}

The forensic medical examiner could specify that a Mental Health Act assessment take place if the patient is unfit and is not already subject to the powers and provisions of the Act. The custody officer should inform the summoned assessment team of all the circumstances surrounding the case and the proposed course of action. In some cases, immediate hospitalisation under section will be recommended. It is envisaged that such a decision be taken only after consultation with the RMO.

As with other individuals arrested and detained at the police station, if the police are unable to complete their investigation within a reasonable time, it may be appropriate to bail the individual to return to the police station at a specified time. Meanwhile, the police will be able to carry on the investigation. If bail is granted, the hospital will be expected to provide or arrange appropriate accommodation and care for the patient. The officer will request that a member of staff undertakes to return the patient to hospital and produce the patient at the police station at the specified time.

A common misconception among police officers is that proceedings through the criminal justice system and continuing care through the mental health services are mutually exclusive. It is therefore fundamentally important that if an informal patient is later detained under the Mental Health Act in the station, the custody officer should be informed promptly that there is still a wish for prosecution to continue. If not, legal proceedings may be discontinued at this point.

Fitness to be interviewed

At the custody officer's discretion, the forensic medical examiner or a psychiatrist can be required to examine the patient's fitness to be interviewed. The patient can be considered unfit for interview if conducting the interview worsens any existing physical or mental illness to a significant degree. Similarly, if anything said or done by the detained person at the time of detention might be considered unreliable in subsequent court proceedings because of the physical or mental state of the detainee, the patient is unfit. In such circumstances, the forensic medical examiner should indicate when the patient should next be examined.

Psychiatric disorders and other relevant factors affecting fitness to be interviewed have been reviewed by Rix (1997). Further factors leading to a conclusion that a patient is unfit to be interviewed include being unable to comprehend a police caution, being disorientated in time, place and person or giving answers that could be misconstrued (Gudjonsson et al, 2000). 


\section{Appropriate adult}

The custody officer must obtain an appropriate adult, as defined in PACE, Code of Practice C 1990 (Home Office, 1995b) to assist in the taking of a statement from a person with a mental disorder. This should occur even if the forensic medical examiner advises that the patient is fit to be interviewed, as it allows the evidence to be obtained in a reliable and fair manner. Failure to follow this procedure can result in evidence not being admissible in court.

\section{The police's decision on prosecution}

\section{The case vignette, continued}

Following interview in the police station, the custody officer rings to tell you that the patient is free to return to hospital. Although she is of the opinion that there is evidential sufficiency, she believes that charging a patient who has a mental disorder is not in the public interest and would not be supported by the CPS. You argue that the patient deliberately attacked a member of staff in a public service, causing injury, and that this had an extensive emotional impact on the victim. Further, it would be beneficial for the patient to confront his responsibility for his action and prosecution would convey a strong message to other patients, staff and the victim. This is also a prevalent offence and it was by luck alone that the injuries were not more serious. You get an agreement that prosecution will now be recommended and that papers will be passed to the CPS.

\section{Case disposal}

Overshadowing the influence of the perceptions, concerns and procedures described above is the police case disposal mechanism (Bayney \& Ikkos, 2002). During this stage, the police officer will decide whether to pursue prosecution, based upon all the factors surrounding the case, including whether prosecution is in the public interest (Box 5). Presence of mental disorder, although a

\section{Box 5 Prosection and the 'public interest'}

A number of factors relating to what is in the public interest influence prosecution:

- The age of the offender

- The mental health of the offender

- The relationship between offender and victim

- Any element of corruption

- The attitude and wishes of the victim

- The likely outcome of the case significant mitigating factor, should never be the only factor considered in reaching a decision about charging. For many police officers, the need to protect the safety of the public is the most important element in reaching a decision.

The overall procedure generates a weighted judgement, which may not justify proceeding with prosecution. Unless otherwise previously agreed, the police will ask that the patient be returned to hospital. Even if charged, the patient is likely to be bailed to return at a future time. Protocols need to be in place for managing patients on bail and liaising with the police following return to hospital.

\section{The Crown Prosecution Service}

This paper focuses on processes and perceptions within the police organisation, but it is important to acknowledge the role of the Crown Prosecution Service. The CPS code guiding prosecution contains criteria similar to those followed by the police (Crown Prosecution Service, 2000). However, although the CPS and the police work closely together, final responsibility for the decision to prosecute rests with the CPS.

There is evidence that in the past, the CPS has discontinued proceedings, provided that appropriate psychiatric care can be arranged (Joseph, 1990), leading to some patients inappropriately avoiding the criminal justice system. However, there is little evidence that in the cases of psychiatric inpatients who offend, rejection by the CPS occurs solely because of the mental health issue. More recent guidance for the CPS strengthens this, specifying that the existence of mental disorder must be weighed against the seriousness of the offence and the possibility that it might be repeated (Home Office, $1995 a)$.

\section{Conclusions}

In-patients who commit crimes present complicated issues for clinical staff. Furthermore, violent inpatients are, in many respects, the most complex in-patient group. Referral to the police further compounds the complexity of their management. Knowledge of police officers' perceptions and procedure will help mental health staff in communicating and cooperating effectively with the police.

Regular liaison with the police can only advance effective teamwork, something that is central to every stage of the management of this demanding group. Underpinning this should be an agreed local protocol promoting clear strategies and a consistent 


\section{Box 6 Practices that should already be in place}

1 Clear guidelines when a patient offends, highlighting factors important in distinguishing which crimes to report

2 Mechanisms for supporting victims or witnesses of crime

3 A working practice with the local police in document form and ready to hand that includes the method by which the police are summoned

4 Full support for staff from the hospital management when offences are reported

5 Inter-agency programmes of joint training with the local police and social services. This facilitates understanding of each discipline, particularly with respect to service provision and resources, management structure, legal concerns, and abilities to contain offenders. Discussion of realistic complex cases advances joint thinking and forges joint approaches

6 Programmes aimed at prevention through ample clinical treatment programmes and a well-controlled environment

7 An identified community liaison police officer in regular contact with the hospital

8 An identified police liaison officer within the mental health service

9 The Care Programme Approach

10 Joint positive approaches to comorbid substance misuse

approach. Other practices should be in place (Box 6), including a police liaison officer appointed by the hospital, who could take on the bulk of the challenging issues for the RMO concerned. The appointment of a community liaison officer within the local police force is also likely to assist communication and the regular updating of helpful and practical mutually agreed protocols.

\section{References}

Bayney, R. \& Ikkos, G. (2002) Police case disposal: an introduction for psychiatrists. Psychiatric Bulletin, 26, 182185.

Carey, S. J. (2001) Police officers' knowledge of, and attitudes towards, mental illness in southwest Scotland. Scottish Medical Journal, 46, 41-42.

Crown Prosecution Service (2000) The Code for Crown Prosecutors. London: Crown Prosecution Service.

Dew, K. \& Badger, S. (1999) Police perceptions of the mental health services and the mentally ill. New Zealand Medical Journal, 112, 36-38.

Department of Health (2000) Managing Violence in Mental Health and Managing Violence in the Community. London: Department of Health.

Dunn, J. \& Fahy, T. A. (1987) Section 136 and the police. Bulletin of the Royal College of Psychiatrists, 11, 224-225.
Eastman, N. \& Mullins, M, (1999) Prosecuting the mentally disordered. Journal of Forensic Psychiatry, 10, 497-501.

Engel, F. \& Marsh, S. (1986) Helping the employee victim of violence in hospitals. Hospital and Community Psychiatry, $37,159-162$

Gudjonsson, G. H., Hayes, G. D. \& Rowlands, P. (2000) Fitness to be interviewed and psychological vulnerability: the views of doctors, lawyers and police officers. Journal of Forensic Psychiatry, 11, 74-92.

Hakeem, A. \& Fitzgerald, B. (2002) A survey of violent and threatening behaviours within an in-patient learning disability unit. Psychiatric Bulletin, 26, 424-427.

Home Office (1995a) Mentally Disordered Offenders: Intraagency Working (Home Office Circular). London: HMSO. - (1995b) Police and Criminal Evidence Act 1994: Codes of Practice. London: HMSO.

Joseph, P. (1990) Mentally disordered offenders: diversion from the criminal justice system. Journal of Forensic Psychiatry, 1, 133-138.

Laberge, D. \& Morin, D. (1995) The overuse of criminal justice dispositions: Failure of diversionary policies in the management of mental health problems. International Journal of Law and Psychiatry, 18, 389-414.

Lanza, M. L. (1983) The reactions of nursing staff to physical assault by a patient. Hospital and Community Psychiatry, 34, 44-47.

Lund, L. E. (1999) What happens when health practitioners report domestic violence injuries to the police? A study of the law enforcement response to injury reports. Violence and Victims, 14, 203-214.

Meadows, G., Calder, G. \& Van Den Bos, H. (1994) Police referrals to a psychiatric hospital: indicators for referral and psychiatric outcome. Australian Psychiatry, 28, 259268.

Menzies, R. (1987) Psychiatrists in blue: police apprehension of mental disorder and dangerousness. Criminology, 25, 429-453.

Metropolitan Police Service (1994) Understanding Mental Disorder. London: Training Design and Research Unit of the Metropolitan Police Service.

Miller, R. D. \& Maier, G. J. (1987) Factors affecting the decision to prosecute mental patients for criminal behaviour. Hospital and Community Psychiatry, 38, 50-55.

Norko, M. A., Zonana, H. V. \& Phillips, R. T. (1991) Prosecuting assaultative psychiatric in-patients. Hospital and Community Psychiatry, 42, 193-195.

Reiner, R. (1992) The Politics of the Police. Hemel Hempstead: Harvester Wheatsheaf.

Rix, K. J. B. (1997) Fit to be interviewed by the police? Advances in Psychiatric Treatment, 3, 33-40.

Ryan, J. \& Poster, E. (1993) Workplace violence. Nursing Times, 89, 38-41.

Smith, J. \& Donovan, M. (1990) The prosecution of psychiatric in-patients. Journal of Forensic Psychiatry, 1, 379-383.

UK Central Council for Nursing, Midwifery and Health Visiting (2002) The Recognition, Prevention and Therapeutic Manage ment of Violence in Mental Health Care. London: UKCC.

Wick, J. M. (2000) Don't destroy the evidence! AORN Journal, 72, 807-818.

\section{Multiple choice questions}

1 Police officers:

a come into regular contact with individuals who have mental disorders

$\mathrm{b}$ are not trained mental health professionals

c should always enforce the law

d usually believe that they have insufficient training in mental illness

e can arrest patients who are detained under the Mental Health Act 1983. 
2 When an in-patient commits an offence, mental health staff should:

a consider proceeding by way of summons in most cases

b always insist on prosecution of the patients

c assess the patient's fitness to interview on the psychiatric ward

d maintain patient confidentiality when discussing the offence with the police

e take the patient off a section of the Mental Health Act before transfer to the police station.

3 Perceptions among police officers include a belief that:

a mental health professionals view prosecution of inpatients as unethical

b taking a patient with a mental disorder from hospital is unsafe

c taking a patient with a mental disorder from hospital is a necessary step before prosecution

d transferring a patient with a mental disorder from hospital to a police station is a disciplinary offence

e dealing with crime committed by a psychiatric inpatient is not a responsibility of the police.

4 Regarding the prosecution of psychiatric in-patients who offend:

a prosecution usually has no direct therapeutic value

$b$ patients that are unfit for interview can still be prosecuted c the final decision to prosecute is made by the police through the case disposal mechanism

$\mathrm{d}$ prosecution may be a form of scapegoating

e the forensic medical examiner makes the final decision on whether prosecution should proceed.

5 When an in-patient is taken to the police station under arrest, the patient may be:

a formally interviewed by the forensic medical examiner

b formally interviewed by an appropriate adult

c formally interviewed by a Crown prosecutor

d formally examined by a psychiatrist

e formally interviewed by the custody officer.

\section{MCQ answers}

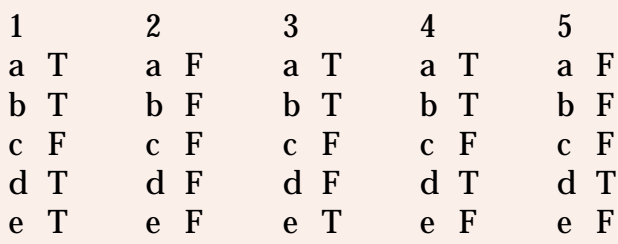

\section{CANFOR}

\section{Camberwell Assessment of Need - Forensic Version}

\section{By Stuart Thomas, Mari-Anne Harty, Janet Parrott, Paul McCrone, Mike Slade and Graham Thornicroft}

CANFOR is a tool for assessing the needs of people with mental health problems who are in contact with forensic services. It is based on the Camberwell Assessment of Need, a widely used needs assessment for people with severe mental health problems. Needs are assessed in 25 areas of life and cover a broad range of health, social, clinical and functional domains. The book includes the rating scales, descriptions of how they were developed and their psychometric properties, administration details, a full training programme, guidance on scoring and blank assessment forms for photocopying. Versions for use in both research and clinical settings are included.

July 2003, 128pp, A4, spiral-bound, ISBN 190124298 6, $£ 75$

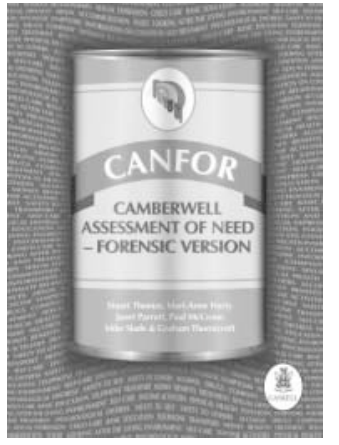

